\title{
Return of auditory function following structural regeneration after acoustic trauma: Behavioral measures from quail ${ }^{1.2}$
}

\author{
Andrew J. Niemiec *, Yehoash Raphael, David B. Moody \\ Kresge Hearing Research Institute, University of Michigan Medical School, 130I East Ann Street, Ann Arhor, MI 48109-(5)506. US.A
}

Received 26 June 1993; Revision received 3 December 1993: Accepted 12 January 1994

\begin{abstract}
After measuring baseline behavioral audiograms, three of four behaviorally trained quail and fifteen untrained cohorts were exposed to a $1.5-\mathrm{kHz}$ octave-band noise at 116-dB SPL for $4 \mathrm{~h}$. The trained birds were tested daily following the exposure and showed a steady recovery of absolute sensitivity with a return to normal absolute thresholds by post-exposure days $8-10$. Thirteen untrained cohorts were sacrificed after various survival times to evaluate the structural condition of the ear. The cohorts all showed regeneration of sensory cells similar to that seen in chicks. The effects of repeated acoustic trauma on recovery of sensitivity were evaluated by re-exposing the three trained birds and two untrained cohorts 106 days after the first exposure. One of the trained birds was exposed a third time, 113 days following the second exposure. The findings demonstrate that, following acoustic trauma, normal sensitivity returns prior to complete structural regeneration of the sensory epithelium and that repeated acoustic trauma may increase the time course of recovery of normal hearing sensitivity.
\end{abstract}

Keywords: Regeneration; Recovery; Noise damage; Hair cells; Animal psychophysics

\section{Introduction}

In contrast to the mammalian organ of Corti, the auditory epithelium of lower animals, such as birds and reptiles, is capable of regenerating following damage from acoustic trauma (Corwin and Cotanche, 1988; Ryals and Rubel, 1988). The regeneration process results in the restoration of hair cells with apparently normal morphology (Cotanche, 1987a; Cotanche and Corwin, 1991) as well as the repair of the tectorial membrane and other structures (Cotanche, 1987b). This phenomenon has important basic and clinical significance, leading to the hope that regeneration can be induced in the human auditory system.

\footnotetext{
* Corresponding author. Fax: (313) 764-0014.

${ }^{1}$ Portions of this paper were presented at the 16th Mid-Winter Meeting of the Association for Research in Otolaryngology in St. Petersburg, FL, February, 1993

${ }^{2}$ This article has previously been published in Hearing Research Volume 75. pp. 209-224. It is reprinted here in its entirety due to at number of errors made at the publishers during the processing of the original manuscript.
}

The extent to which structural regeneration results in normal auditory function in the intact animal is not well understood. Behavioral and electrophysiological measures have provided evidence of recovery of sensitivity in ears with newly regenerated hair cells following aminoglycoside ototoxicity (Hashino and Sakabe, 1989; Tucci and Rubel, 1990). It is likely that regeneration of hair cells in birds subjected to acoustic overstimulation also results in recovery of hearing sensitivity (Hashino et al., 1988), however, in that case, some of the performance improvements could occur as a result of mechanisms of recovery from temporary threshold shift independent of the regeneration of hair cells (McFadden and Saunders, 1989).

Behavioral techniques can provide a comprehensive measure of hearing with the potential of measuring more complex aspects of hearing using a consistent procedure. Therefore, developing behavioral procedures to evaluate return of function offers the potential of much more thorough evaluation of the return of auditory function.

An important secondary question regarding recovery of function is concerned with the effects of repeated 
acoustic trauma on recovery. Although electrophysiological measures have provided evidence of recovery of sensitivity following repeated acoustic overstimulation (Adler et al., 1993), Marsh et al. (1990) have estimated that as few as $22 \%$ of hair cells are replaced following acoustic trauma. In addition, Ryals et al. (1989) have found that ganglion cell loss continues for at least ninety days following acoustic trauma. These findings suggest that repeated acoustic overstimulation may compromise the ear's ability to recover normal auditory function. Changes in the time course and/or extent of recovery following repeated acoustic trauma would indicate that the regenerative capability of the ear has been altered.

This study used behavioral and histochemical techniques to relate the recovery of sensitivity following one or more noise exposures to the morphology of the regenerated epithelia.

\section{Materials and methods}

Subjects were nineteen mature quail (Coturnix coturnix). Four of the quail were trained to report the detection of pure tones in a positive-reinforcement behavioral procedure modeled after Okanoya and Dooling (1985). The remaining quail were untrained cohorts that were used for histological purposes to evaluate the condition of the ear following acoustic trauma and recovery. All subjects were individually housed and had free access to water. Untrained quail had free access to food while trained quail worked for food and were supplemented with additional food rations after the testing session.

The trained birds were tested in one of two behavioral testing chambers. The chambers consisted of a wire-mesh testing cage housed inside a sound-attenuating box. The testing cage contained two keys and a food dispenser. The keys were mounted six inches apart on the front panel of the testing cage and were six inches above the cage floor. The food dispenser (BRS/LVE) was mounted between the keys such that the access hole to the dispenser was centered between the keys, three inches above the cage floor. The keys were lit to indicate when subjects could initiate a trial. A loudspeaker was suspended directly above the testing cage for stimulus presentation. One testing apparatus was equipped with a Krohn-Hite 4030R programmable oscillator and allowed testing of the behavioral subjects at nine frequencies in a single session, whereas the other testing apparatus was equipped with four manual oscillators (three Hewlett-Packard 200CDRs and one Hewlett-Packard 204C), allowing testing at only four frequencies during a session. Stimuli were three-second pure tones fed to a tone switch with a $20-\mathrm{ms}$ rise /fall time and were calibrated using a lock-in amplifier system that allowed determination of the level of the tones in $\mathrm{dB}$ SPL. Stimulus presentation, timing, and the monitoring of the animal's responses were under computer control.

\section{Behavioral methods}

The behavioral procedure required the bird to peck an 'observing' key for a 1-7 second random time interval in order to produce a tone. This observing response maintained the bird in a relatively fixed position so that the sound level at the bird's ear did not fluctuate greatly from trial to trial. The random time interval decreased the likelihood that the bird could produce correct reporting responses based on timing behavior without attending to the tone. Once a tone was presented, the bird had three seconds in which to peck the separate 'reporting' key to indicate detection of the tone. Correct detections of tones were rewarded with brief access to food.

In order to monitor the animal's guessing behavior, catch trials comprised $25 \%$ of all test trials. During a catch trial, no tone was presented, and the bird was to continue pecking the observing key. Brief access to food was intermittently provided at the end of a catch trial. The probability with which the subject was reinforced for catch trial 'holding' was adjusted to keep the subject's catch trial response rate below $20 \%$. Incorrect responses, such as pecking the reporting key in the absence of a tone, resulted in a 10-second timeout from the experiment. The key lights were turned off during the timeout, indicating that a new trial could not be initiated.

Daily absolute threshold estimates were measured for each of the birds using a one-up/one-down tracking rule (Levitt, 1971). This rule tracks the level of the tone that gives $50 \%$ correct detection. According to this tracking rule, the level of the tone was decreased after each correct response and increased after each incorrect response. The step size for the increase or decrease in level was $10 \mathrm{~dB}$. The quail were tested at each frequency until six reversals from detection to non-detection or vice-versa occurred. The first two reversals were discarded and the midpoints of the remaining four reversals were averaged in order to derive an absolute threshold estimate for the frequency.

The quail were tested for $60-90 \mathrm{~min}$ per day. This schedule typically resulted in $2-3$ sets of threshold estimates when nine test frequencies were used and 4-6 sets of threshold estimates when four frequencies were tested. If catch trial response rates were less than or equal to $20 \%$ for the entire testing session, all thresholds at a given frequency were averaged to determine a daily threshold. If catch trial response rates were greater than $20 \%$ for the entire testing session, only those thresholds that had corresponding catch 
trial response rates less than or equal to $20 \%$ were averaged to determine a daily threshold. A final absolute threshold for a test frequency was determined when the quail met a stability criterion which required that four out of five threshold estimates fall within \pm 5 $\mathrm{dB}$ of the median threshold estimate. When this requirement was met, the median of the five stable threshold estimates was taken as the absolute threshold at that frequency. A typical test frequency had a standard deviation of approximately $5 \mathrm{~dB}$ when behavioral thresholds were averaged across a 2 -week period.

\section{Absolute Thresholds for 4 Coturnix Quail}

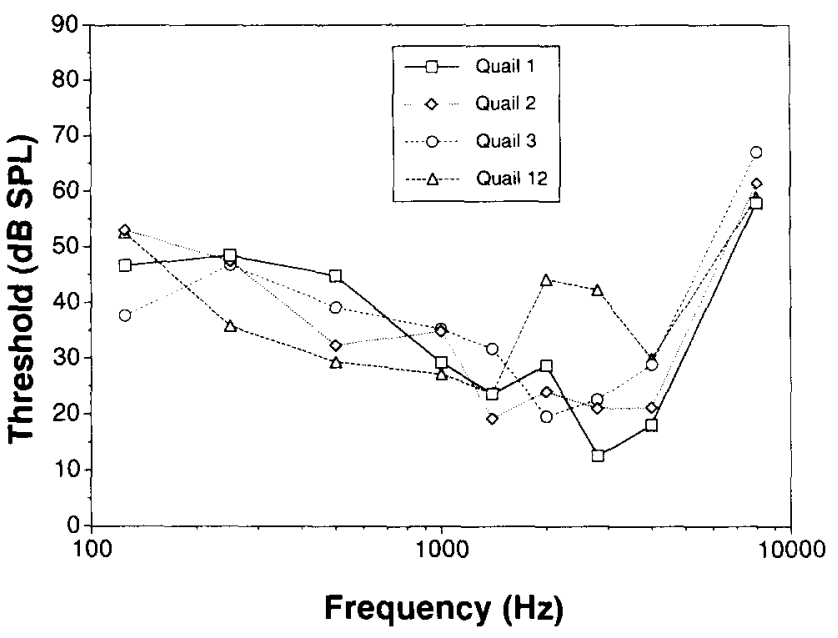

Absolute Thresholds of Various Birds

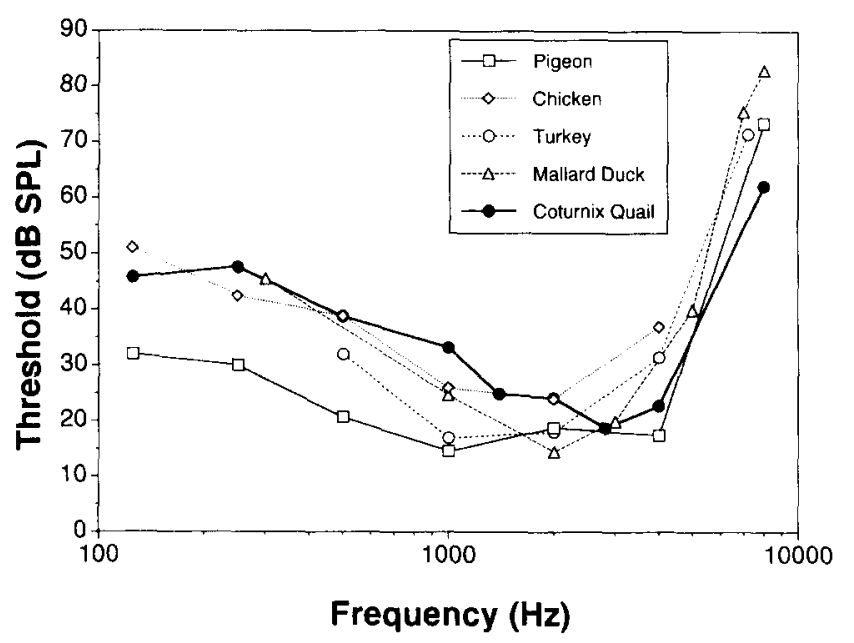

Fig. 1. The audiograms of the four trained birds used in this study are shown in the top panel. The bottom panel shows a comparison of the average quail audiogram with audiograms measured from similar types of birds (Trainer, 1946 (mallard duck); Heise, 1953 (pigeon); Stebbins, 1970 (pigeon); Harrison and Furumoto, 1971 (pigeon); Maiorana and Schleidt, 1972 (turkey); Hienz et al., 1977 (pigeon); Goerdel-Leich and Schwartzkopff, 1984 (pigeon); Grey and Rubel, 1985 (chicken)). The pigeon audiogram was derived by averaging the data from the studies cited above.

\section{Acoustic trauma and recovery}

Once a stable baseline audiogram had been measured, the trained bird and its untrained cohorts were exposed to a $1.5-\mathrm{kHz}$ octave-band noise at $116-\mathrm{dB} \mathrm{SPL}$ for $4 \mathrm{~h}$. This exposure had previously been determined to produce well-defined, localized lesion patterns similar to those seen in chicks (Raphael, 1992). Three of the four trained birds were exposed in this fashion. The fourth bird was dropped from the experiment because his catch trial response rate increased and could not be brought below $20 \%$. Following the noise exposure, the trained animals were tested using the procedure described above. Each quail's pre-exposure audiogram served as its baseline in computing threshold shifts following noise exposure.

Threshold estimates from the first few days following the exposure were more variable than those derived prior to exposure. In order to measure postexposure threshold shifts as reliably as possible, threshold estimates following exposure were derived as described previously except that the required minimum number of tracking reversals for the acceptance of a threshold was reduced from six to four. Decreasing the number of reversals required for acceptance of a threshold increased the number of estimates used to derive a threshold at a given frequency, increasing the reliability of the threshold. In addition, when thresholds were being computed, each threshold estimate at a given test frequency was weighted by the number of reversals comprising that estimate. In this way, threshold estimates where the bird worked more consistently (as demonstrated by a greater number of reversals) were given a greater weight in the final threshold. That is, if two thresholds were measured at a particular test frequency during the same testing session and the first threshold estimate was based on four reversals while the second estimate was based on two reversals, the first threshold estimate was multiplied by four and the second estimate was multiplied by two, the two totals were summed, and the grand total was divided by six, the number of reversals that comprised the grand total. This final number, which is functionally equivalent to averaging all the transitions, served as that day's threshold estimate at that test frequency.

Day of recovery was defined as the first day following exposure on which there was no threshold shift greater than $10 \mathrm{~dB}$ at any test frequency. Once the trained birds showed recovery of sensitivity, thresholds were derived in the usual manner. Daily testing continued until the birds again yielded stable post-exposure absolute thresholds at all test frequencies. These stable post-exposure thresholds measured following recovery of sensitivity served as the new baselines for subsequent noise exposures.

To examine the effects of repeated acoustic trauma on recovery of sensitivity, the trained birds were re-ex- 


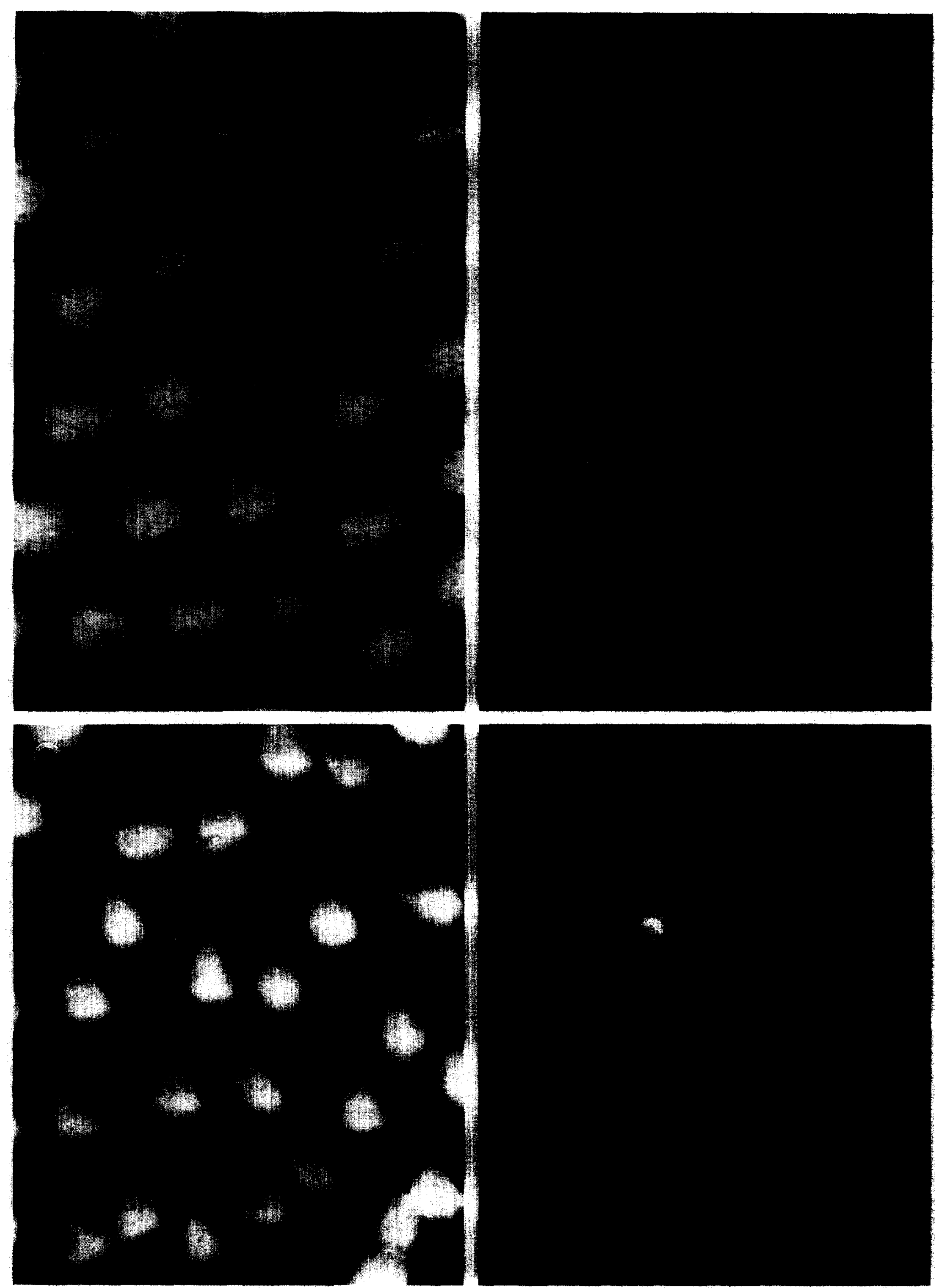


posed to the same noise 106 days after the first exposure. One of these birds was then exposed a third time, 113 days after the second exposure. Recovery of sensitivity following re-exposure was measured as described above.

\section{Histological methods}

Thirteen of the fifteen untrained cohorts were allowed to survive for up to 35 days following the exposure. The two remaining cohorts were re-exposed 106 days following the first exposure and allowed to survive for three or thirteen days following the second exposure prior to being sacrificed.

The extent of damage and regeneration in the untrained cohorts was evaluated using histo- and immuno-cytochemical techniques. The animals were deeply anesthetized with chloral hydrate or BEuthanasia and perfused intracardially with $3 \%$ paraformaldehyde in $0.15 \mathrm{M}$ phosphate buffer at $\mathrm{pH}$ 7.35. The temporal bones were removed from the skull and the basilar papillae were freed from surrounding bone. The tegmentum vasculosum was removed to gain surface view at the basilar papilla. All tissues were permeabilized in $0.3 \%$ Triton X-100 in PBS for 2-5 min, blocked against non-specific immunoreactivity and stained with phalloidin which labeled actin, Hoechst which labeled DNA, and cingulin-specific antibodies which labeled cingulin (Raphael, 1993). The phalloidin stain was useful for assessing apical cell contour and morphology of the cuticular plate and stereociliary bundle. The DNA-specific marker (Hoechst) was used to label all DNA in the tissue, revealing nuclei of all cells in the basilar papilla and chromosomes in all dividing cells. The tight junction-specific marker was used to determine the integrity of the reticular lamina and the confluence of the tissue facing the lumen bordering the basilar papilla.

Whole-mount papillae were then placed on glass slides in $60 \%$ glycerol in sodium carbonate buffer $(\mathrm{pH}$ 8.5) with p-phenylenediamine as an anti-bleach agent and covered with a coverslip. The tissue was analyzed with a Leitz Orthoplan fluorescence microscope using
$16 \times, 50 \times$ and $100 \times$ objectives and photographed using Kodak T-max 400 film exposed at 1600 ASA.

\section{Results and discussion}

Absolute thresholds of the four trained birds used in this study are shown in the top panel of Fig. 1. Three of the four birds have very similar thresholds and exhibit greatest sensitivity between 1 and $4 \mathrm{kHz}$. The fourth bird, Quail 12, shows similar thresholds at all frequencies except those in the vicinity of $2-3 \mathrm{kHz}$, where this bird shows a $20-25 \mathrm{~dB}$ decrease in sensitivity relative to the other three birds. Quail 12 was retested several times and this decrease in sensitivity at $2-3 \mathrm{kHz}$ remained a stable feature of the bird's audiogram.

The bottom panel of Fig. I shows a comparison of the typical quail audiogram, derived by averaging the audiograms of quails $1-3$, with audiograms measured from similar types of birds. Quail 12's audiogram was omitted from the average because it does not fit the norm. The average quail audiogram is typical of ground-dwelling birds in general, with the quail being slightly less sensitive at the low frequencies and slightly more sensitive at high frequencies.

The results of histochemical analysis on control tissue from unexposed quail are shown in Fig. 2. The use of whole-mounts for histochemical analysis allowed visualization of the entire basilar papilla, while triplelabeling proved to be an excellent method for assessing the tissue organization, distribution of junctional complexes, and location and integrity of cell nuclei. In control tissues, F-actin (microfilaments) was present in the stereocilia and the cuticular plate (terminal web) of every hair cell (Fig. 2A), as previously described in the chick (Tilney et al., 1983; Raphael, 1991). Hair cells were normally organized in rows with similar spacing. Co-localization of actin (Fig. 2A) and DNA (Fig. 2B) in control tissues made it possible to locate the nucleus in relation to the actin cytoskeleton of each cell, as previously described in the chick basilar papilla (Raphael,

\footnotetext{
Fig. 2. Fluorescent micrographs of whole-mounts of the normal quail basilar papilla labeled with phalloidin and Hoechst (A and B. respectively) or phalloidin and cingulin-specific antibodies (C and D, respectively). (A): The phalloidin label reveals actin in the stereocilia and cuticular plate of each hair cell and in the junctional complexes between the cells of the basilar papilla. The stereocilia appear splayed and spread when the tectorial membrane is removed. The arrow points at the cell depicted in B. (B): The DNA-specific label reveals nuclei in the basilar papilla. At the focal plane immediately beneath the reticular lamina, laminar organization of hair cell nuclei is evident. Arrow points at nucleus of the cell marked with arrow in A. (C): When the tectorial membrane remains in situ, the stereocilia bundles retain their tightly packed organization. Actin is present in the stereocilia, cuticular plate and adherens type junctional complexes. (D): The distribution of cingulin in the reticular lamina marks the continued line of tight junctions between cells of the basilar papilla. Arrows in C and D point at the same cell. Note the pentagonal shape of hair cells, the slender apical surfaces of supporting cells which surround the hair cells, the relatively uniform size of the hair cell surfact and stereocilia bundle and the orderly lines of cells in this tissue. Bar, $5 \mu \mathrm{m}$.
} 
Quail 1 - Recovery from First Noise Exposure

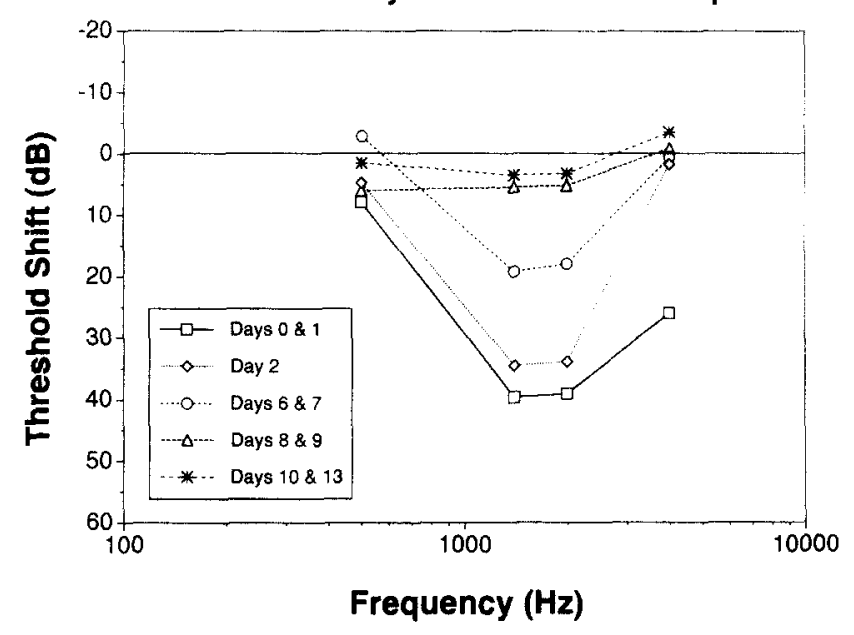

Quail 2 - Recovery from First Noise Exposure

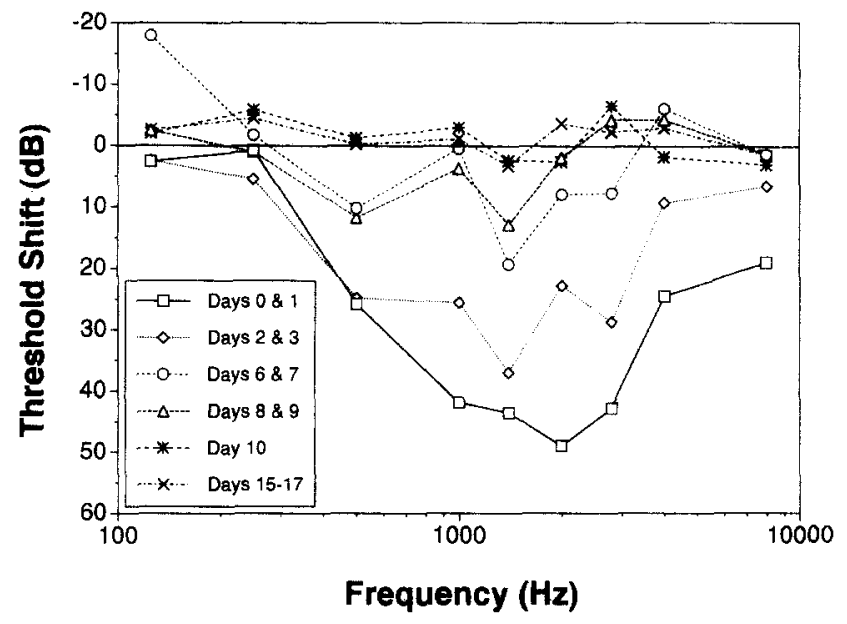

Quail 12 - Recovery from First Noise Exposure

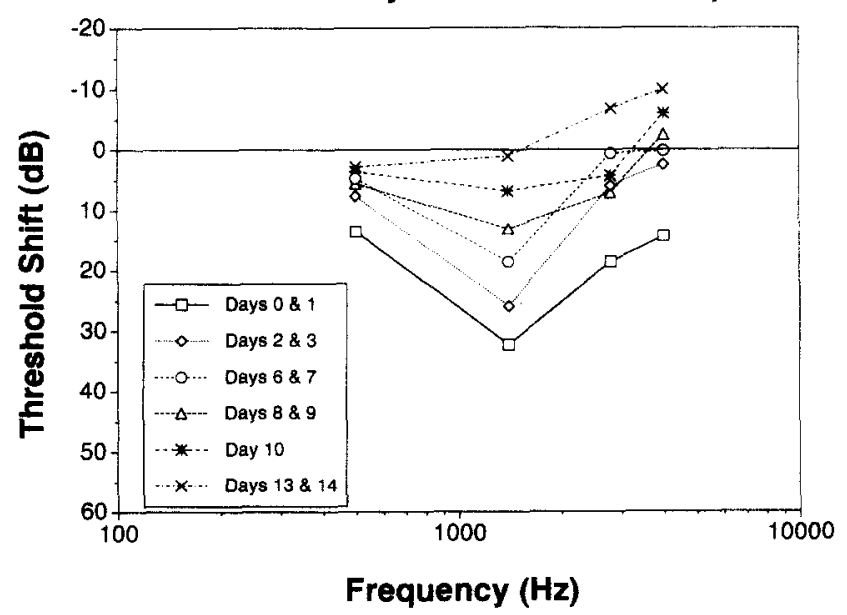

1992). Normal quail hair cells exhibited round nuclei organized in rows, visible at a focal plane immediately beneath the luminal surface (Fig. 2B). Supporting cell nuclei, also labeled by the Hoechst DNA stain, were located at a deeper focal plane closer to the basement membrane (not shown). Thus, nuclei of cells in the basilar papilla had a laminar distribution, with hair cell nuclei immediately beneath the reticular lamina and supporting cell nuclei beneath them, closer to the basal lamina, as previously reported (Raphael, 1992). Co-localization of actin (Fig. 2C) and cingulin (Fig. 2D) was valuable for delineating the contours of apical intercellular borders in the basilar papilla. Cingulin, a protein specific to tight junctions (Citi et al., 1988; Citi et al., 1989), labels homophilic (supporting cell-supporting cell) and heterophilic (supporting cell-hair cell) junctions at the focal plane of the reticular lamina in the organ of Corti (Raphael and Altschuler, 1991) and the basilar papilla (Raphael, 1993).

Recovery of sensitivity following a four-hour exposure to a 116-dB SPL octave-band noise centered at 1.5 $\mathrm{kHz}$ is presented in Fig. 3. Some of the threshold shift functions in Fig. 3 have been averaged across two or more days in order to reduce the amount of day-to-day variability and to represent the recovery process more clearly. The top panel shows recovery of sensitivity for Quail 1 at four test frequencies in the vicinity of the octave-band noise. Quail 1 was tested at only four test frequencies following the noise exposure because, prior to exposure, this bird had catch trial response rates just below $20 \%$. Testing at a reduced number of frequencies following exposure helped maintain low catch trial response rates during recovery. On day 0 , this bird exhibited a $45-\mathrm{dB}$ hearing loss at frequencies in the vicinity of the octave-band noise. Quail 1 was then tested daily and showed a steady recovery of absolute sensitivity with a return to normal absolute thresholds by day 8 post-exposure. The middle panel shows recovery of sensitivity for Quail 2 at all nine test frequencies. On day 0 , this bird exhibited a $55-\mathrm{dB}$ hearing loss at frequencies in the vicinity of the octave-band noise. Quail 2 also showed a steady recovery of absolute sensitivity with a return to normal absolute thresholds by day 10 post-exposure. Threshold shifts measured on

Fig. 3. Recovery of sensitivity for three trained birds following a 4-hour exposure to a 116-dB SPL octave-band noise centered at 1.5 $\mathrm{kHz}$. The top panel shows recovery for Quail 1 at four test frequencies. The middle panel shows recovery for Quail 2 at all nine test frequencies. The bottom panel shows recovery for Quail 12 at four test frequencies. All three birds recovered normal hearing sensitivity within 8-10 days following this first exposure. 
days 15-17 demonstrated that Quail 2's sensitivity remained stable following recovery. The bottom panel shows recovery of sensitivity for Quail 12 at four test frequencies in the vicinity of the octave-band noise. This bird was tested at only four frequencies because it was tested in the behavioral apparatus that had only four oscillators. Threshold shifts measured on day 0 were unreliable because of high catch trial responding; however, this bird exhibited a $35-\mathrm{dB}$ hearing loss at frequencies in the vicinity of the octave-band noise on day 1 post-exposure, which was comparable to the threshold shifts shown by the other two behavioral birds on day 1. Like the other two trained birds, Quail 12 showed a steady recovery of absolute sensitivity with a return to normal absolute thresholds by day 10 postexposure.

The next four figures show tissue from the untrained cohorts at various times following the noise exposure. Fig. 4 shows histochemical analysis of tissue immediately following the noise exposure. The area of the lesion was similar in most animals and was approximately $100 \times 50-60$ cells. The lesion was approximately $0.8 \mathrm{~mm}$ long in the proximal-distal plane. In the superior-inferior plane, the lesion spanned the entire basilar papilla in some areas which we refer to as the center of the lesion.

The center of the lesion was located $40 \%$ of the distance from the proximal (high frequency) end of the basilar papilla, approximately $1 \mathrm{~mm}$ from the base. In this area, $60-90 \%$ of the hair cells were missing. The lesion involved mostly short hair cells but some cells in the tall hair cell area were also damaged or lost. The pathology included missing hair cells replaced by expanded supporting cells (Figs. $4 \mathrm{~A}$ and $\mathrm{B}$ ) in a pattern similar to that previously described in the chick (Cotanche, 1987a,b; Marsh et al., 1990; Raphael, 1991). Nuclei of cells in this area of the lesion displayed signs of degeneration. These nuclei were ovoid and contained large aggregates of DNA adjacent to the nuclear membrane (Fig. 4C).

The center of the lesion was flanked on both the proximal and distal sides by a peripheral lesion with less severe pathology than that found in the center. In the peripheral lesion, the extent of hair cell loss decreased as the distance from the center of the lesion increased. At the edges of the peripheral lesion hair cell loss was minimal but stereocilia bundles were pathological. Many of the surviving hair cells had elongated stereocilia and occasional stress links. Stress links are contacts between stereocilia of neighboring cells that have previously been described in the chick basilar papilla (Raphael et al., 1994). Many supporting cells in the peripheral lesion were expanded exhibiting a stress-associated figure eight (SAFE) (Raphael, 1993) (Fig. 4D).

Fig. 5 shows the basilar papilla of birds killed 4 days after the exposure. In these birds, hair cells in the periphery of the lesion appeared relatively normal but supporting cell morphology was altered (Fig. 5A). Close to the center of the lesion, most hair cells had elongated stereocilia and had established intercellular contacts with stress links (Fig. 5B). Stress links and elongated stereocilia were also found in the center of the lesion, where several hair cells survived the trauma (Fig. 5C). Mitotic cells were found in most ears at this stage (Fig. 5D). The pattern of cell division in the traumatized quail basilar papilla was similar to that described in the chick (Raphael, 1992).

Fig. 6 shows tissue from birds allowed to survive for two weeks following the noise exposure. In these birds, hair cell nuclei in the area of the lesion were nearly confluent (Fig. 6A); however, the organization of the tissue was not as orderly as in normal animals. Giant hair cells with stress links were found in the vicinity of embryonic hair cells. Close to the periphery of the lesion, reorganization of supporting cell junctions was evident. Small hair cells were observed in regions where missing hair cells could not be detected (Fig. 6B). Nevertheless, the surface of the basilar papilla was covered by hair cells (Fig. 6C).

Fig. 7 shows tissue from birds allowed to survive for five weeks following the trauma. In these birds, new hair cells were generated and hair cell loss was not evident. In most cases it was not possible to distinguish between pre-existing and new hair cells. Nevertheless, several cells in the center of the lesion still had elongated stereocilia and stress links, and some supporting cell expansion was still evident (Fig. 7A). In the periphery of the lesion tissue organization was nearly normal, whereas in the center of the lesion slight stereocilia abnormalities were found on some cells (Fig. 7B).

Fig. 8 shows recovery of sensitivity for the three trained quail following a second noise exposure that took place 106 days after the first exposure. The top panel shows recovery of sensitivity for Quail 1 at four test frequencies in the vicinity of the octave-band noise. On day 0 , this bird exhibited a $45-\mathrm{dB}$ hearing loss at frequencies in the vicinity of the octave-band noise. As with the first exposure, Quail 1 was tested daily and showed a steady recovery of absolute sensitivity with a return to normal absolute thresholds by day 16 post-exposure. The middle panel shows recovery of sensitivity for Quail 2 at all nine test frequencies. On day 0, this bird exhibited a $60-\mathrm{dB}$ hearing loss at frequencies in the vicinity of the octave-band noise. Quail 2 was also tested daily and showed a steady recovery of absolute sensitivity with a return to normal absolute thresholds by day 12 post-exposure. The bottom panel shows recovery of sensitivity for Quail 12 at all nine test frequencies. On day 0, Quail 12 exhibited a 45-dB hearing loss at frequencies in the vicinity of the octave-band noise. Daily testing following the exposure 


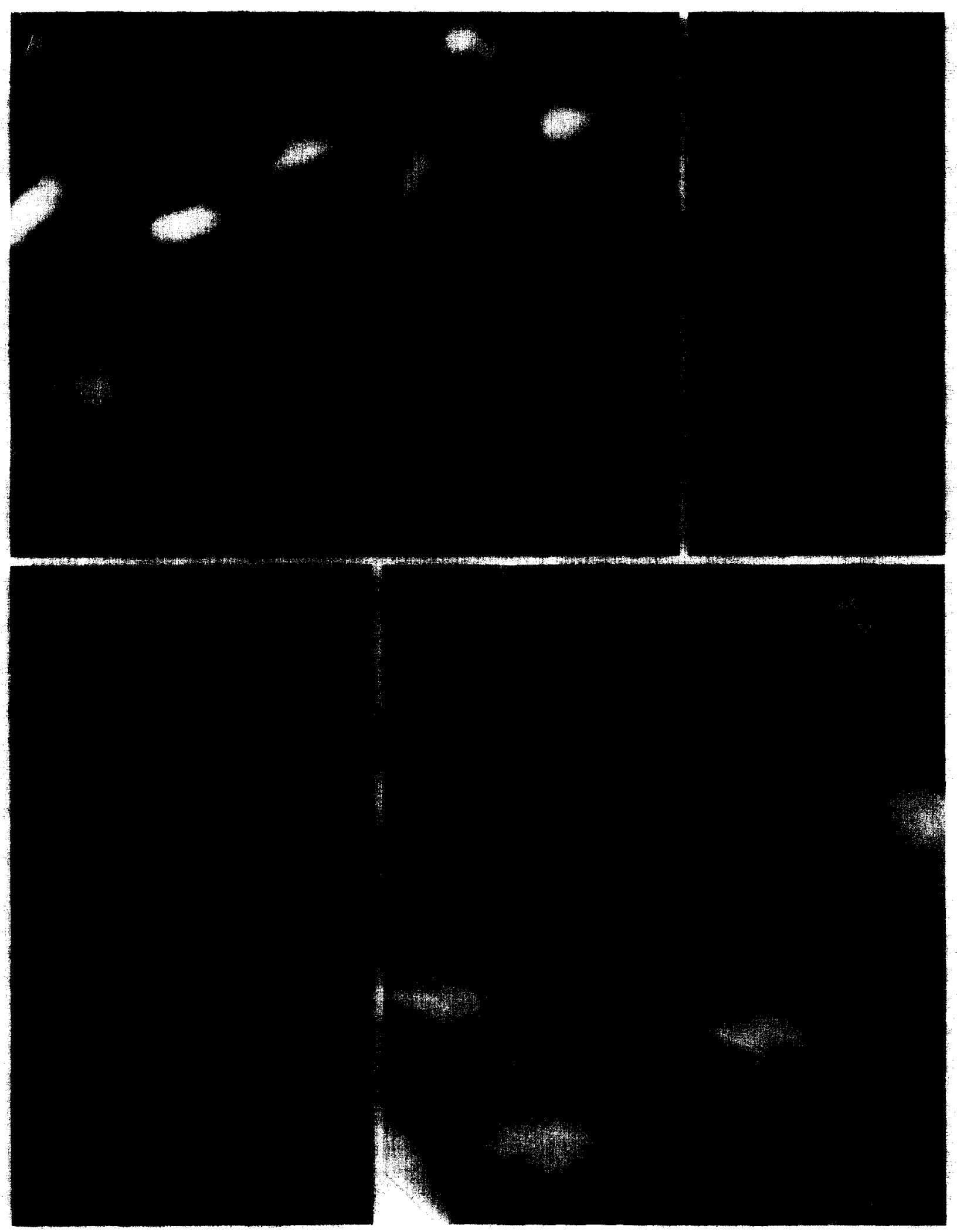

Fig. 4. Whole-mounts of the basilar papilla of quail killed immediately after the noise exposure and labeled with phalloidin (A and D). cingulin-specific antibodies (B) and Hoechst (C). (A): In the center of the lesion several missing hair cells are replaced by expanded supporting cells (s). (B): The pattern of the intercellular junctions at the reticular lamina is altered compared to normal. (C): At the focal plane of hair cell nuclei, some nuclei are missing and others are in the process of degeneration, with DNA aggregating at the periphery of the nucleus. (D): No hair cells appear to be missing at the periphery of the lesion, but supporting cells have altered apical shapes, appearing like figure-eights with a stress-associated figure eight (SAFE) in the middle. Stereocilia bundles are longer than usual in this area. Bars, $5 \mu \mathrm{m}$. 

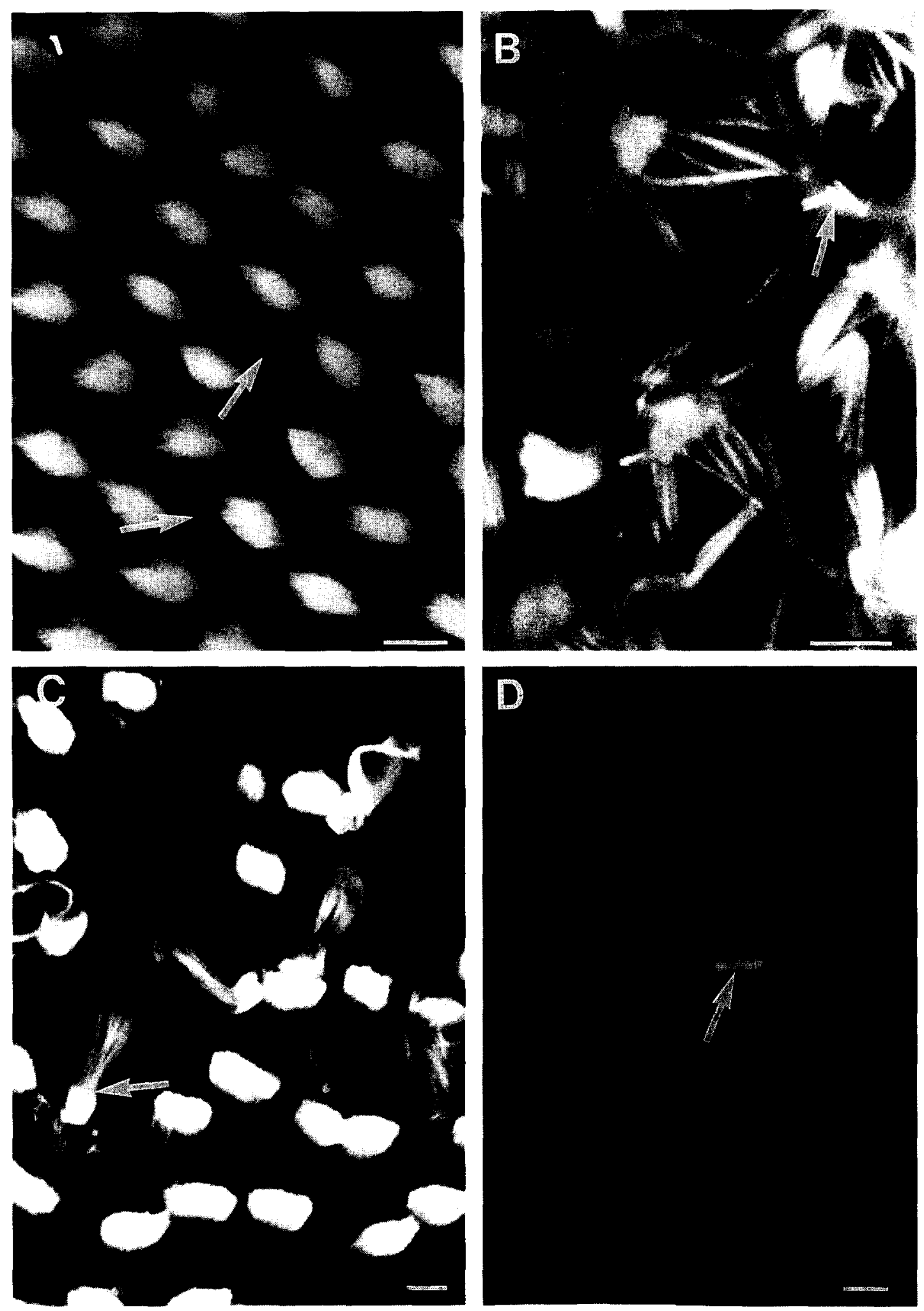

Fig. 5. Whole mounts of the quail basilar papilla 4 days after the noise exposure, labeled with phalloidin (A-C) and Hoechst (D). (A): In the periphery of the lesion supporting cells appear like figure-eights. Arrows point at central (constricted) portions of figure-eights. Hair cell loss is not evident. (B): In a region closer to the center of the lesion, the size of hair cells is slightly distorted and some hair cells bear stereocilia in more than one bundle. Many stereocilia are elongated, forming 'stress links' in which stereocilia tips are in contact with tips of stereocilia from a neighboring cell. (C): In the center of the lesion, expanded supporting cells occupy spaces of missing hair cells. Surviving hair cells display an irregular apical contour, elongated stereocilia and stress links at the stereocilia tips (arrow). (D): Chromosomes of a dividing supporting cell in the center of the lesion. Bars, $5 \mu \mathrm{m}$. 

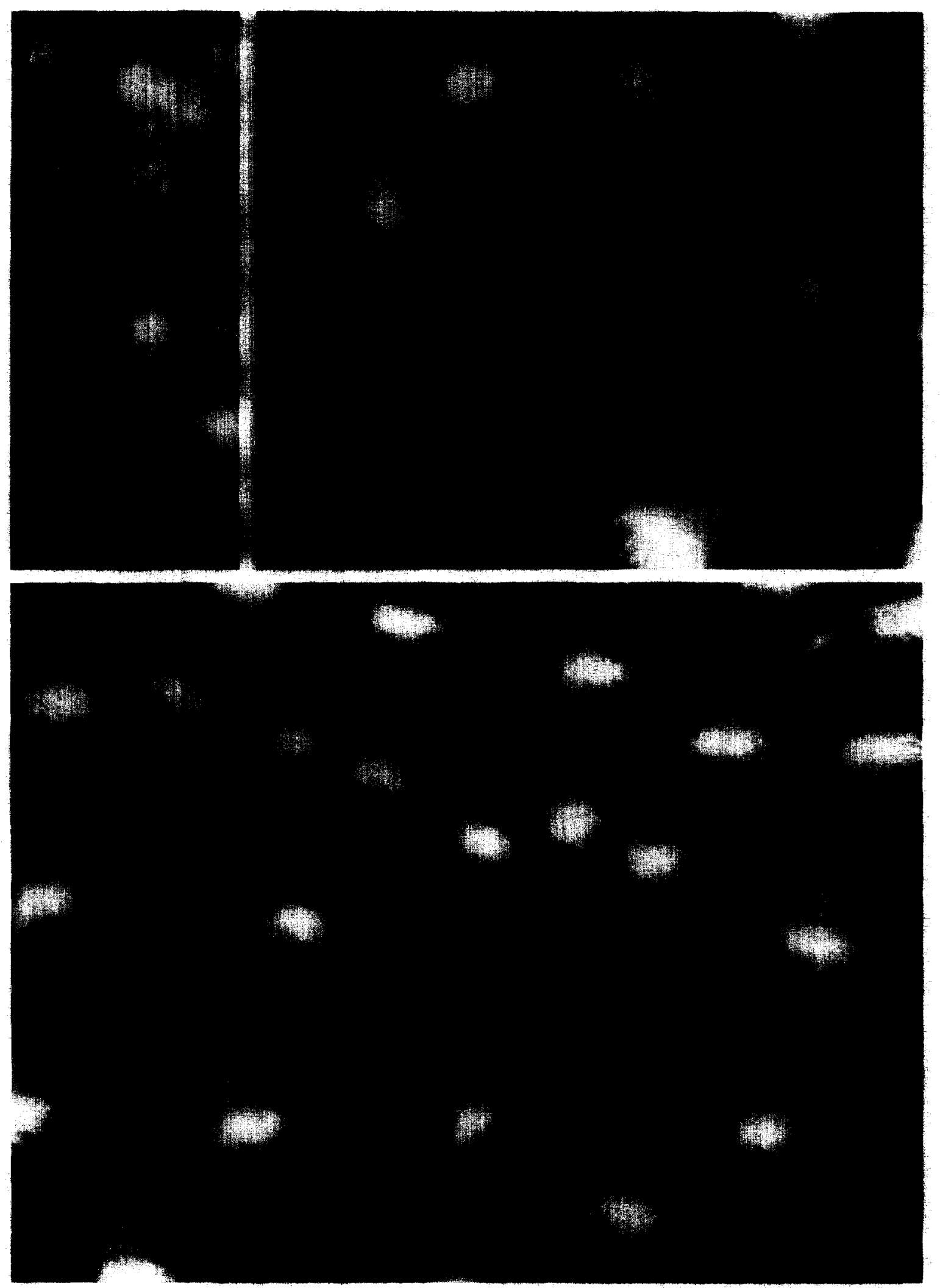

Fig. 6. Hoechst (A) and phalloidin (B, C) labeled whole-mounts of a quail basilar papilla 2 weeks after the noise exposure. (A): At the focal plane of $r$ air cell nuclei, the DNA label reveals relatively normal distribution of nuclei with slightly irregular organization. (B): Hair cells with irregular morphology and giant hair cells $(\mathrm{g})$ are present along with a small embryonic-like pair of hair cells (arrows) in the periphery of the lesion, where hair cell loss is not evident. (C): In the center of the lesion, coverage of the basilar papilla surface with hair cells is incomplete and expanded supporting cells (s) can still be detected. Immature hair cells are found in pairs (two arrows) or singles (one arrow). Bars. $5 \mu \mathrm{m}$. 
showed a steady recovery of absolute sensitivity. However, on post-exposure day 16, the bird's catch trial response rate increased and could not be brought down to $20 \%$ or less prior to complete behavioral recovery. This precluded a precise determination of the date of recovery of normal sensitivity for this bird. Although a 13-dB threshold shift still remained on day 15 post-exposure, this was within $3-\mathrm{dB}$ of the operating definition of recovery used in this study and indicated that recovery of sensitivity was imminent.

The two untrained cohorts that were exposed a second time were allowed to survive for three or thirteen days. The area of the lesion in these two animals is virtually identical to that seen in animals sacrificed at comparable times following the initial exposure.

Recovery of hearing sensitivity following a third noise exposure is shown in Fig. 9. The third exposure took place 113 days following the second exposure and resulted in a $65-\mathrm{dB}$ threshold shift on day 0. Quail 2 showed steady recovery of absolute sensitivity with a return to normal absolute thresholds by day 14 post-exposure.

Fig. 10 shows threshold shift as a function of time at a test frequency in the region of maximum threshold shift for each of the three birds. The top panel shows pre-exposure threshold shifts as well as the threshold shifts for Quail 1 at the $2-\mathrm{kHz}$ test frequency for both noise exposures. Immediately following the exposures there was a $45-$ to $47-\mathrm{dB}$ threshold shift followed by a fairly rapid recovery for the first 3-4 days following the exposures. The recovery process then continued at a slower rate until normal absolute sensitivity returned. The middle panel shows similar data at $2-\mathrm{kHz}$ for Quail 2 for all three noise exposures. Immediately following the exposures there was a 51 - to $65-\mathrm{dB}$ threshold shift followed by rapid recovery for the first
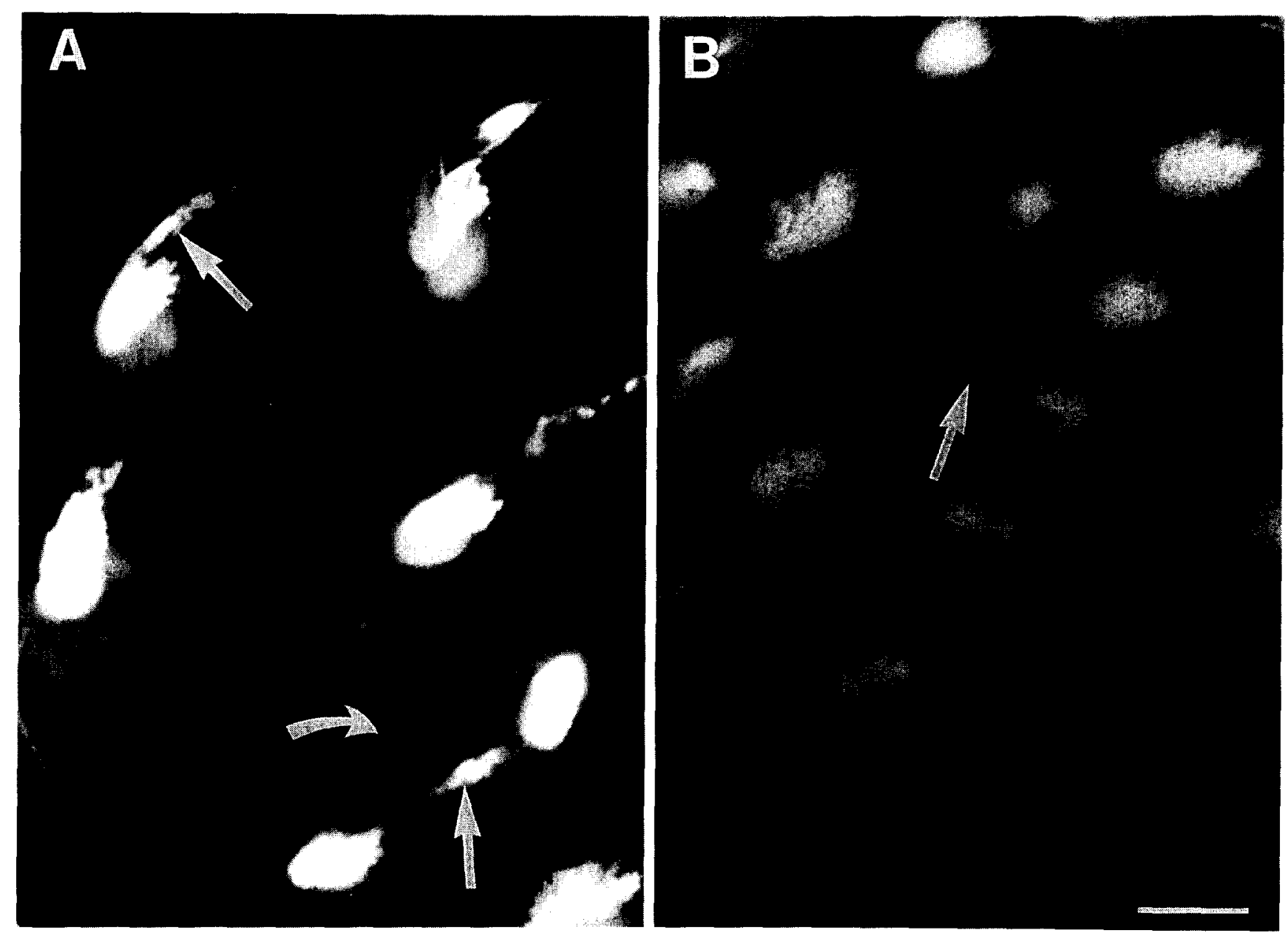

Fig. 7. A phalloidin-labeled quail basilar papilla 5 weeks after noise exposure. (A): In the periphery of the lesion several hair cells still have irregular stereocilia bundles. (B): In the center of the lesion most hair cells have regular size and shape but some stereocilia irregularities are still observed. Bar, $5 \mu \mathrm{m}$. 
Quail 1 - Recovery from Second Noise Exposure

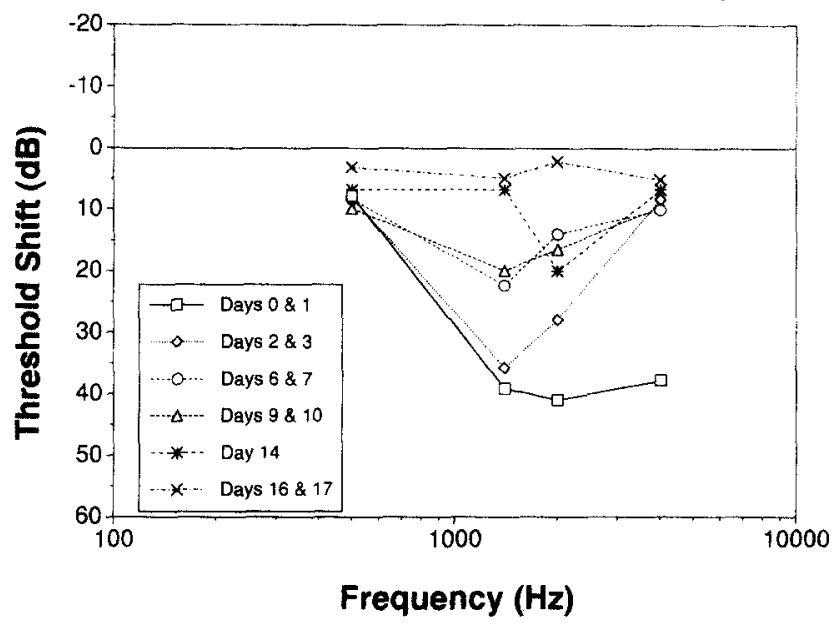

Quail 2 - Recovery from Second Noise Exposure

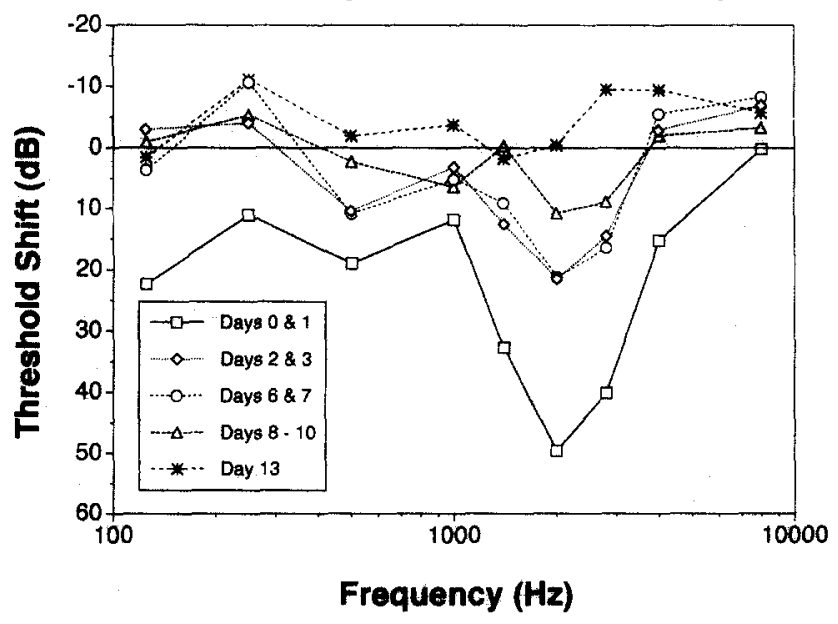

Quall 12 - Recovery from Second Nolse Exposure

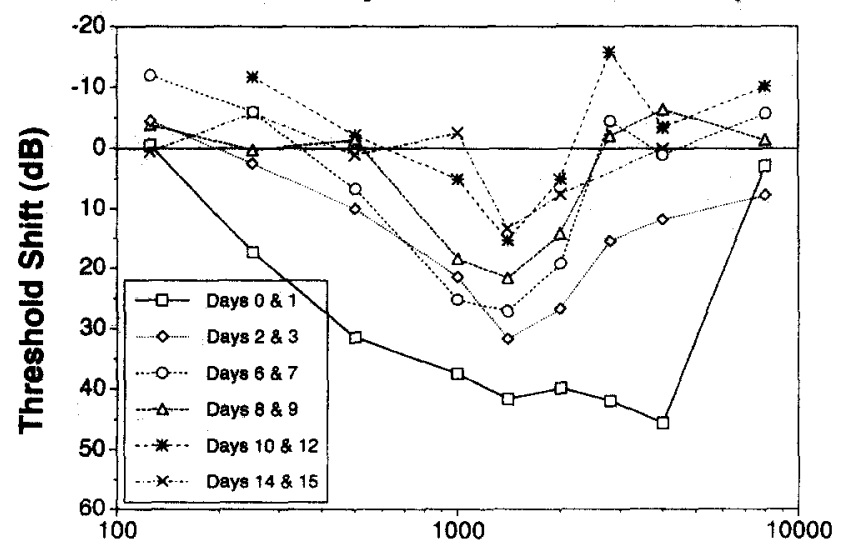

Frequency (Hz)
Quail 2 - Recovery from Third Noise Exposure

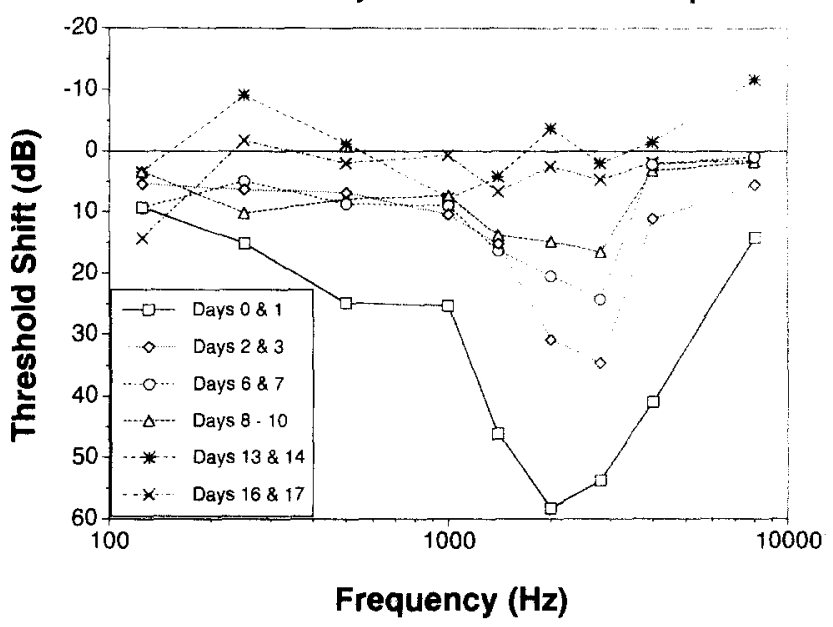

Fig. 9. Recovery of sensitivity following a third 4-hour exposure to a 116-dB SPL octave-band noise centered at $1.5-\mathrm{kHz}$. The third exposure took place 113 days after the second exposure. This figure shows recovery for Quail 2 at all nine test frequencies. Quail 2 recovered normal hearing sensitivity by day 14 following the third exposure.

3-4 days following the exposures. The recovery process then continued at a slower rate until normal absolute sensitivity returned. The bottom panel shows data from Quail 12 at the $1.4-\mathrm{kHz}$ test frequency following both noise exposures. Quail 12's threshold shift at $1.4 \mathrm{kHz}$ following the first noise exposure was unreliable because of high catch trial responding; however, the bird's threshold shift on day 1 post-exposure is comparable to thresholds shifts seen from the other two behavioral birds, suggesting that the threshold shift at day 0 was probably comparable to that seen in the other birds. The second noise exposure resulted in a 44-dB threshold shift immediately following the exposure. Although not as obvious in this bird's data, Quail 12 also shows more rapid recovery of sensitivity during the first three days following exposure, with slower recovery after day 3 post-exposure. The slope of the recovery function at the $2-\mathrm{kHz}$ testing frequency across all three animals and all exposures was $9.8 \mathrm{~dB} /$ day for

Fig. 8. Recovery of sensitivity for the three trained birds following a second 4-hour exposure to a 116-dB SPL octave-band noise centered at $1.5-\mathrm{kHz}$. The second exposure took place 106 days after the first exposure. The top panel shows recovery for Quail 1 at four test frequencies: The middle panel shows recovery for Quail 2 at all nine test frequencies. The bottom panel shows recovery for Quail 12 at all nine test frequencies. Quails 1 and 2 recovered normal hearing sensitivity within 12-16 days following the second exposure. Ouail 12 's behavior began to deteriorate on post-exposure day 16 , precluding a precise determination of the date of recovery of normal sensitivity. 
days $0-3$ and $2.6 \mathrm{~dB} /$ day for days $6-10$, indicating that recovery occurs more rapidly during the first few days following the acoustic trauma.
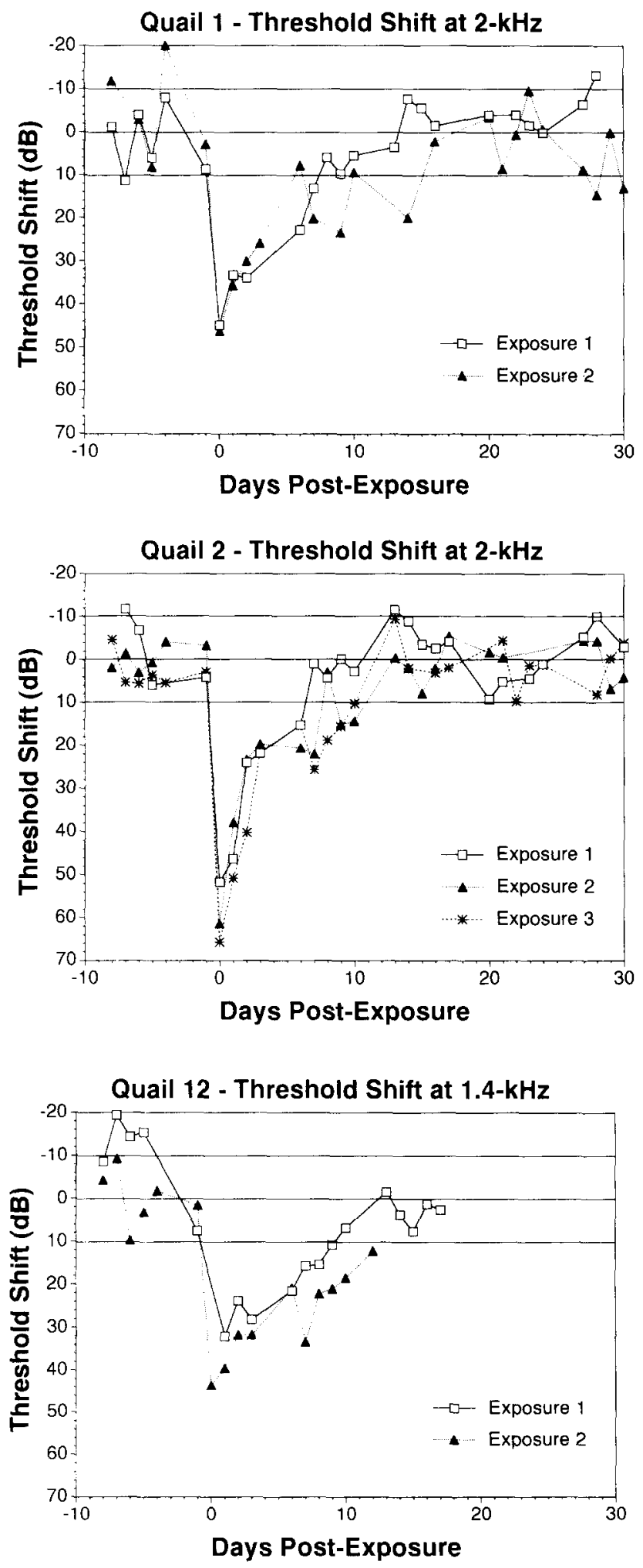

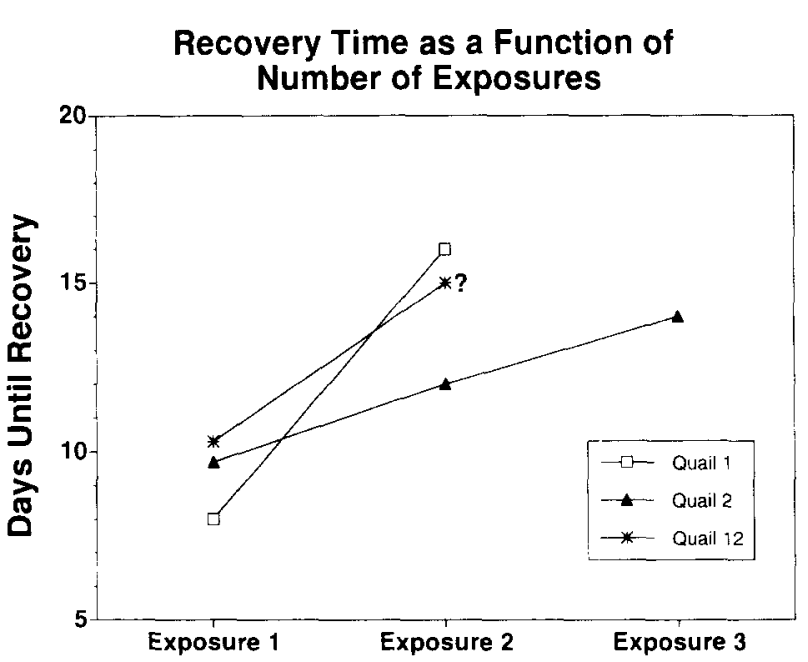

Fig. 11. The number of days until recovery of normal hearing sensitivity as a function of the number of exposures for each of the three trained birds. The trend in these data indicates that recovery time increases slightly with each additional exposure. Although a precise day of recovery could not be determined for Quail 12 following the second exposure, recovery was not yet complete by day 15 post-exposure. This is indicated by a question mark next to the data point shown for this bird's recovery from the second exposure.

The number of days until recovery of normal hearing sensitivity as a function of the number of exposures for each of the three birds is shown in Fig. 11. Although a precise day of recovery could not be determined for Quail 12 following the second noise exposure, recovery had not yet occurred by day 15 post-exposure. This is indicated by a question mark next to the data point shown for this bird's recovery from the second exposure. Although these data are limited, there appears to be a trend showing that each exposure results in a slightly longer recovery time. The present data are too scarce to determine whether this trend is indeed meaningful; however, changes in the time course of recovery following repeated acoustic trauma would indicate that the regenerative capability of the ear has been altered and might suggest that repeated acoustic trauma may be compromising the ear's ability to recover normal auditory function.

Fig. 10. Threshold shift as a function of time at a test frequency in the vicinity of maximal threshold shift for each of the three birds. The top panel shows pre- and post-exposure threshold shifts for Quail 1 at the $2-\mathrm{kHz}$ test frequency for both exposures. The middle panel shows pre-and post-exposure threshold shifts for Quail 2 at the $2-\mathrm{kHz}$ test frequency for all three exposures. The bottom panel shows pre-and post-exposure threshold shifts for Quail 12 at the $1.4-\mathrm{kHz}$ test frequency for both exposures. All three birds show a rapid recovery averaging approximately $10 \mathrm{~dB} /$ day on post-exposure days $0-3$. After post-exposure day 3 , a slower recovery averaging approximately $3 \mathrm{~dB} /$ day is evident. 


\section{General discussion}

Although behavioral and electrophysiological measures have provided evidence of recovery of sensitivity in ears with newly regenerated hair cells following acoustic overstimulation (Hashino et al., 1988; McFadden and Saunders, 1989; Adler et al., 1993), it is possible that some of the performance improvements could have occurred as a result of mechanisms of recovery from temporary threshold shift independent of the regeneration of hair cells (McFadden and Saunders, 1989). This study examined changes in structure and function following one or more noise exposures to relate recovery of sensitivity, measured using behavioral techniques, to the morphology of the regenerating sensory epithelium, evaluated using histochemical techniques, thus providing insight into the possible mechanisms involved in the recovery of normal sensitivity following acoustic trauma. Studying regeneration and recovery of function following repeated acoustic trauma allows specification of the extent to which the ear's ability to recover normal auditory function is compromised by multiple episodes of damage and repair.

The measures of threshold shift following the initial noise exposure depend on the trained birds' pre-exposure baselines. With the exception of Quail 12's thresholds in the $2-3 \mathrm{kHz}$ region, the baseline absolute thresholds measured in this experiment show little variability between animals. This, combined with a comparison of the pre-exposure absolute threshold data with similar data from other species of birds, confirms that the pre-exposure absolute thresholds measured in this study are reasonable and reliable. The quail audiograms are stable and typical of ground-dwelling birds.

The exposure paradigm developed for use in these experiments resulted in severe behavioral threshold shift and yielded considerable damage in a well-defined region of the basilar papilla. Threshold shifts following initial noise exposure ranged from $45-65 \mathrm{~dB}$, with the noise-exposed birds showing a steady recovery of normal absolute sensitivity over the next 8-10 days.

The histochemical approach used in these experiments was a very powerful analytical tool in that it allowed thorough analysis of the entire basilar papilla. Triple-labeling allowed assessment of tissue organization, stereocilia, distribution of junctional complexes, and location and integrity of cell nuclei. The histological analysis of normal, unexposed birds revealed that quail morphology is similar to that found in the chick. No hair cells were missing, stereocilia were of uniform size, and the organization of nuclei was uniform. The histochemical labels also revealed the shape and condition of hair cells and supporting cells following noise exposure, which were comparable to those seen in the chick after similar exposures (Raphael, 1992; 1993). The site of the lesion was similar in all birds as was the extent of the damage. Cell division was found on post-exposure day 3 and new hair cells were nevet observed prior to post-exposure day 4. By 14 days post-exposure, areas with hair cell loss were no longer visible but tissue organization was not vet normal. By 35 days post-exposure, the organization was nearly normal, however, there were still some hair cells which showed stress responses in their stereocilia. These data suggest that these types of morphological perturbances are compatible with normal hearing sensitivity, raising questions about the functional relevance of the highly ordered tissue in the basilar papilla and suggesting that behavioral examination of other aspects of hearing change is needed.

Repeated acoustic trauma also resulted in threshold shifts of 45-65 dB, with the re-exposed birds showing a steady recovery of normal absolute sensitivity over the next 12-16 days. Complete recovery followed each exposure and susceptibility to morphological damage due to repeated exposures was similar to the susceptibility to the initial exposure. The area of the lesion following the second exposure was nearly identical to that observed following comparable survival times after the initial exposure.

Measures of threshold shift as a function of the time course of recovery at a frequency in the vicinity of the noise exposure indicate that the recovery process has two phases. During the first three days following an exposure, the trained birds showed a rapid recovery of approximately $10 \mathrm{~dB} /$ day. Following the initial rapid recovery of sensitivity, the birds displayed a much slower recovery of approximately $3 \mathrm{~dB} / \mathrm{day}$. While this slower recovery of sensitivity is presumably due to gradual recovery of other elements of the basilar papilla including the development of the new hair cells, the morphological results show that the first phase of recovery is not dependent on repopulation of hair cells, suggesting that other structures are involved.

There are several possible explanations for the initial rapid recovery of sensitivity. First, it conforms with results showing that recovery of sensitivity may have been due to the recoupling of the surviving hair cells to the tectorial membrane (McFadden and Saunders, 1989; Adler et al., 1993). Alternatively, the afferent nerve fibers which innervate the tall hair cells may have been temporarily swollen or damaged but recovered over this time course. Although the morphology of the afferent nerve fibers was not examined in these experiments, future research should involve assessment of damage to the afferent fibers following acoustic trauma and recovery. The differential function of the tall and short hair cells may lead to a third possible explanation for the rapid initial recovery. The short hair cells sustained most of the damage following the acoustic trauma, however, the short hair cells may not be necessary to show a substantial recovery of function 
during the first few days following acoustic trauma. Perhaps in the first few days, tall hair cells that were damaged due to the exposure have recovered to the point where they have again become functional, resulting in a rapid increase in sensitivity.

In general, threshold shifts and recovery following repeated noise exposures were similar to those observed following the first noise exposure; however, the amount of time necessary for recovery of sensitivity appeared to increase slightly following each exposure. Although the available data indicate a trend showing an approximate three day increase in recovery time with each additional exposure, they are based on an extremely small sample size. It is difficult to evaluate the significance of this increase in recovery time following each exposure and the increase may reflect factors, such as aging, that are unrelated to the multiple exposure. Further experiments are being conducted to determine whether this trend is indeed meaningful.

The use of behavioral techniques in studies relating function to structure is important because they provide a comprehensive measure of hearing sensitivity and can also provide a uniform methodology with which other complex aspects of hearing can be assessed. Future studies of this type will need to examine more complex auditory processes as well as responses of the neural elements and the extra-cellular matrix to the changes in hearing resulting from acoustic trauma. Developing behavioral procedures to evaluate other types of auditory processing will potentially provide a thorough evaluation of the return of auditory function.

\section{Acknowledgments}

The authors would like to thank Dr. Yu Wang, Ms. Catherine Thompson, and Ms. Elizabeth Sturm for technical assistance and Dr. Sandra Citi (Cornell University Medical School, New York) for kindly donating anti-cingulin antibodies. This work was supported by a Deafness Research Foundation grant (AJN) and by NIDCD grants R01 DC01634 (YR) and R01 DC01746 (DBM).

\section{References}

Adler, H.J., Poje, C.P. and Saunders, J.C. (1993) Recovery of auditory function and structure in the chick after two intense pure tone exposures. Hear. Res. 71, 214-224.

Citi, S., Sabanay, H., Jakes, R., Geiger, B. and Kendrick-Jones, J. (1988) Cingulin, a new peripheral component of tight junctions. Nature 333, 272-276.

Citi, S., Sabanay, H., Kendrick-Jones, J. and Geiger, B. (1989) Cingulin: characterization and localization. J. Cell Sci. 93. 107122.
Corwin, J.T. and Cotanche, D.A. (1988) Regeneration of sensory hair cells after acoustic trauma. Science 240, 1772-1774.

Cotanche, D.A. (1987a) Regeneration of hair cell stereociliary bundles in the chick cochlea following severe acoustic trauma. Hear. Res. 30, 181-196.

Cotanche, D.A. (1987b) Regeneration of the tectorial membrane in the chick cochlea following severe acoustic trauma. Hear. Res. 30, 197-206.

Cotanche, D.A. and Corwin, J.T. (1991) Stereociliary bundles reorient during hair cell development and regeneration in chick cochlea. Hear. Res. 52, 379-402.

Goerdel-Leich, A. and Schwartzkopff. J. (1984) The auditory threshold of the pigeon (Columba livia) by heart rate conditioning. Naturwissenschaften 71, S98.

Gray, L. and Rubel, E.W. (1985) The development of absolute thresholds in chickens. J. Acoust. Soc. Am. 77, 1162-1172.

Harrison, J.B. and Furumoto, L. (1971) Pigeon audiograms: Comparison of evoked potential and behavioral thresholds in individual birds. J. Audit. Res. 11, 33-42.

Hashino, E., Sokabe, M. and Miyamoto. K. (1988) Frequency specific susceptibility to acoustic trauma in the budgerigar (Melopsittacus undulatus). J. Acoust. Soc. Am. 83, 2450-2453.

Hashino, E. and Sokabe, M. (1989) Kanamycin induced low-frequency hearing loss in the budgerigar (Melopsittacus undulatus). J. Acoust. Soc. Am. 85, 289-294.

Heise, G.A. (1953) Auditory thresholds in the pigeon. Am. J. Psychol. 66, 1-19.

Hienz, R.D., Sinnott, J.M. and Sachs, M.B. (1977) Auditory sensitivity of the red-winged blackbird (Agelaius phoeniceus) and brown-headed cowbird (Molothrus ater). J. Comp. Physiol. Psychol. 91, 1365-1376.

Levitt, H. (1971) Transformed up-down methods in psychoacoustics. J. Acoust. Soc. Am. 49, 467-477.

Maiorana, V.A. and Schleidt, W.M. (1972) The auditory sensitivity of the turkey. J. Audit. Res. 12, 203-207.

Marsh, R.R., Xu, L., Moy, J.P. and Saunders, J.C. (1990) Recovery of the basilar papilla following intense sound exposure in the chick. Hear. Res, 46, 229-238.

McFadden, E.A. and Saunders. J.C. (1989) Recovery of auditory function following intense sound exposure in the neonatal chick. Hear. Res. 41, 205-216.

Okanoya, K. and Dooling, R.J. (1985) Colony differences in auditory thresholds in the canary (Serinus canarius). J. Acoust. Soc. Am. $78,1170-1176$

Raphael, Y. (1991) Damage to the tectorial membrane may protect chick hair cells from noise overstimulation. Hear. Res. 53. 173184.

Raphael, Y. (1992) Evidence for supporting cell mitosis in response to acoustic trauma in the avian inner ear. J. Neurocytol. 21, $663-671$.

Raphael, Y. (1993) Reorganization of the chick basilar papilla following acoustic trauma. J. Comp. Neurol. 330, 521-532.

Raphael, Y. and Altschuler, R.A. (1991) Modulation of cytoskeletal and junctional proteins during hair cell degeneration. Cell. Motil. $18,215-227$.

Raphael. Y., Wang, Y. and Lee, M.K. (1994) Intercellular contacts between chick stereocilia after acoustic overstimulation. Hear. Res. 73, 85-91.

Ryals, B.M. and Rubel, E.W (1988) Hair cell regeneration after acoustic trauma in adult Coturnix quail. Science 240, 1774-1776.

Ryals, B.M., Ten Eyck, B. and Westbrook. E.W. (1989) Ganglion cell loss continues during hair cell regeneration. Hear. Res. 43, 81-90.

Stebbins, W.C. (1970) Studies of hearing and hearing loss in the monkey. In: W.C. Stebbins (Ed.), Animal Psychophysics: The Design and Conduct of Sensory Experiments. AppletonCentury-Crofts, New York. 
Tilney, L.G., Egelman, E.H., DeRosier, D.J. and Saunders, J.C. (1983) Actin filaments, stereocilia and hair cells of the bird cochlea. II. The packing of actin filaments in the stereocilia and in the cuticular plate and what happens to the organization when stereocilia are bent. J. Cell. Biol. 96, 822-34.
Trainer, J.E. (1946) The auditory acuity of certain hirds. Unpublished Doctoral Dissertation, Cornell University.

Tucci, D.L. and Rubel, E.W (1990) Physiological status of regenterated hair cells in the avian inner ear following aminoglycoside ototoxicity. Otolaryngol. Head Neck Surg. 103, 443-450. 